\title{
Effect of Particle Size of Powders Ground by Ball Milling on Densification of Cordierite Ceramics
}

\author{
Masae NAKAHARA, Yoshihito KONDO and Kenya HAMANO ${ }^{\dagger}$ \\ Kagawa Industrial Technology Center, 587-1, Goto-cho, Takamatsu-shi, Kagawa 761-8031
コーディエライトセラミックスの䋊密化に及ぼすボールミル粉砕原料粉末の粒子径の影響 中原理栄・近藤祥人・濱野健也 ${ }^{\dagger}$
香川県工業技術センター, 761-8031 高松市郷東町 587-1

\begin{abstract}
Mixtures of calcined kaolin, calcined talc and alumina were ground to submicron particle size by ball milling, and the effect of particle size of the ground mixtures on the densification behavior of a cordierite sintered body was studied. As the particle size of the ground mixtures became smaller, the raw material powders were mixed more uniformly and the formation temperature of $\alpha$-cordierite became lower. Dense and pore-free sintered bodies were obtained by firing ground mixtures with particle size smaller than 0.39 $\mu \mathrm{m}$ at temperatures as low as $1200^{\circ} \mathrm{C}$. Cordierite sintered bodies prepared from mixtures with particle size $0.39 \mu \mathrm{m}$ or smaller by grinding natural raw materials had bending strengths ranging from $140-160 \mathrm{MPa}$, and these values were larger than that of cordierite glass-ceramics reported by Hayashi et al. ${ }^{1)}$ The thermal expansion coefficients of dense, high-strength cordierite bodies increased, because anisotropic thermal expansion could not lower the amount of thermal expansion in the pore-free body.
\end{abstract}

[Received September 11, 1998; Accepted January 20, 1999]

Key-words : Cordierite, Particle size, Ground mixture, Densification, Bending strength, Thermal expansion coefficient

1. Introduction

Cordierite ceramics are useful materials with a low thermal expansion coefficient. However, it is difficult to make a dense cordierite body with high strength using natural raw materials, because the difference between the crystallization and decomposition temperatures for cordierite is very small in a sintering process. Although cordierite sintered bodies produced as glass-ceramics ${ }^{1)-3)}$ or prepared from raw materials by the sol-gel method, are predicted to have high strength,4)-7) the preparation processes are complicated and usually require a high cost. Recently, it was reported that dense cordierite ceramics were made from kaolinite and basic magnesium carbonate, ${ }^{8)}$ or ultrafine particles of magnesium hydroxide prepared by the precipitation method. ${ }^{9), 10)}$

In order to develop a preparation method for dense cordierite bodies with high strength from natural raw materials, we have been studying the microstructure and the physical properties of cordierite bodies prepared from calcined kaolin, calcined talc and alumina. We have reported the following results elsewhere. ${ }^{11)-13)}$ Talc grains dissolved and gave residual pores of a similar size during the sintering process of a cordierite body. ${ }^{11)}$ As the particle size of ground talc became smaller, the pore size and the porosity of the sintered body decreased and its mechanical strength increased. ${ }^{12)}$ Furthermore, the sintered body became denser with decreasing particle size of the ground kaolin in the same manner as the ground talc. ${ }^{13)}$ The reaction process that occurred in the mixture composed of several kinds of preground powders was very complicated, and it was difficult to remove pores from the sintered body even if mixtures from the finely ground powders were used.

In the present study, mixtures that are prepared from calcined kaolin, calcined talc and alumina are ground by ball milling for various durations, and the effect of the particle size of ground mixtures on the microstructure and the

\section{元東京工業大学}

連絡先 : 194-0043 東京都町田市成瀬台 3-31-10

3-31-10, Narusedai, Machida-shi, Tokyo 194-0043 physical properties of the sintered bodies is examined.

\section{Experiments}

Starting raw materials were Georgia kaolin $\left(\mathrm{Al}_{2} \mathrm{O}_{3}\right.$. $2 \mathrm{SiO}_{2} \cdot 2 \mathrm{H}_{2} \mathrm{O}$, Sumitomo, SSK), talc from Santon Province in China $\left(3 \mathrm{MgO} \cdot 4 \mathrm{SiO}_{2} \cdot \mathrm{H}_{2} \mathrm{O}\right.$, Sobue Clay, Steatalc) and $\alpha$ alumina $\left(\mathrm{Al}_{2} \mathrm{O}_{3}\right.$, Showa Denko K.K., AL-160SG). Kaolin and talc were calcined at $1000^{\circ} \mathrm{C}$ for $5 \mathrm{~h}$. Figure 1 shows the procedure for preparing the ground mixtures. Calcined kaolin was ground to an average particle size of $1 \mu \mathrm{m}$ by wet ball milling in ethanol with an alumina pot and alumina balls of $3 \mathrm{~mm}$ in diameter. Calcined talc was ground also to an average particle size of $1 \mu \mathrm{m}$ in the same manner. $\alpha$ alumina with an average particle size of $0.5 \mu \mathrm{m}$ was mixed with the mixture of ground kaolin slurry and talc slurry to give the following cordierite composition ratio of $\mathrm{MgO}$ : $\mathrm{Al}_{2} \mathrm{O}_{3}: \mathrm{SiO}_{2}=13.2: 37.8: 49.0$ mass $\%$, which was reported to give the lowest thermal expansion coefficient by Lachman et al. ${ }^{14)}$ After grinding these mixtures for $24,72,120$, 168 and $240 \mathrm{~h}$, their particle size distributions were measured using a particle size analyzer (Shimadzu Corp., SA-CP3L) based on the centrifugal sedimentation method. The chemical compositions of the ground mixtures were determined by the low dilution fusion method using an Xray fluorescence spectrometer (Rigaku Denki, RIX 2000).

Then each ground mixture was mixed with 2 mass\% binder (Chukyo Yushi, Seruna SE604). The mixed slurry was concentrated using a hot plate with a stirrer, dried at $80^{\circ} \mathrm{C}$, and then passed through a $175 \mu \mathrm{m}$ sieve to produce granules. The granules were pressed uniaxially into pellets of $14 \mathrm{~mm}$ in diameter and rectangular specimens of $50 \times 25 \times 3 \mathrm{~mm}$ at $30 \mathrm{MPa}$. The pellets were sintered at $1050,1100,1150,1200,1250,1300,1350$ and $1400^{\circ} \mathrm{C}$, each for $1 \mathrm{~h}$.

Apparent porosity of the sintered bodies was measured by the Archimedes immersion method in water. Crystalline phases were identified by X-ray diffraction analysis (Philips, PW1729). To estimate the quantitative changes of the crystalline phases in the sintered bodies, X-ray intensities of the following diffraction peaks for several 


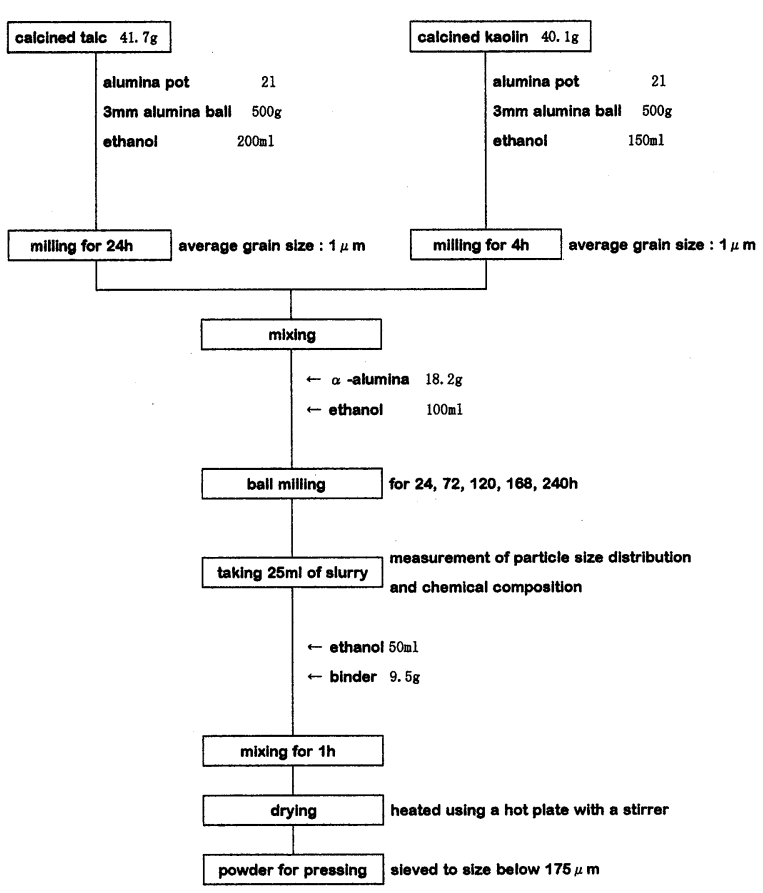

Fig. 1. Procedure for preparing ground mixture.

crystalline phases were measured, that is, 121 reflection for mullite, 420 reflection for enstatite, 012 reflection for corundum, 111 reflection for cristobalite, 311 reflection for spinel, 244 reflection for sapphirine and 211 reflection for $\alpha$ cordierite. The microstructure of the sintered bodies was observed using a scanning electron microscope (JEOL, JSM-840).

The rectangular specimens were sintered at 1300 and $1350^{\circ} \mathrm{C}$ for $1 \mathrm{~h}$, and then were cut, using a diamond cutting wheel, into bending test pieces $(40 \times 4 \times 2 \mathrm{~mm})$. The six bending test pieces for each sintering temperature and each ground mixture were subjected to the three-point bending test. Furthermore, thermal expansions of the specimens were measured by thermomechanical analysis (Shinku Riko, TMA9000) at a heating rate of $10^{\circ} \mathrm{C} / \mathrm{min}$ in the temperature range from 50 to $900^{\circ} \mathrm{C}$.

\section{Results and discussion}

3.1 Chemical composition and average particle size of ground mixtures

Table 1 shows the chemical compositions of the ground mixtures. The mixtures were prepared from natural raw materials such as i.e., kaolin and talc, so it is expected that the mixtures contain impurities such as $\mathrm{Fe}_{2} \mathrm{O}_{3}, \mathrm{TiO}_{2}, \mathrm{CaO}$, $\mathrm{Na}_{2} \mathrm{O}$ and $\mathrm{K}_{2} \mathrm{O}$. The total amount of these impurities in the ground mixtures is about $1.4-1.6$ mass\% regardless of grin-

Table 1. Chemical Composition of Ground Mixtures

\begin{tabular}{cccccccccc}
\hline $\begin{array}{c}\text { grinding time } \\
\text { hour }\end{array}$ & $\mathrm{MgO}$ & $\mathrm{Al}_{2} \mathrm{O}_{3}$ & $\begin{array}{c}\mathrm{SiO}_{2} \\
\text { mass\% }\end{array}$ & $\begin{array}{c}\mathrm{Fe}_{2} \mathrm{O}_{3} \\
\text { TiO }\end{array}$ & $\mathrm{CaO}$ & $\mathrm{Na}_{2} \mathrm{O}$ & $\mathrm{K} 2 \mathrm{O}$ \\
$\mathbf{2 4}$ & 12.9 & 37.3 & 48.4 & 0.33 & 0.78 & 0.17 & 0.10 & 0.06 \\
$\mathbf{7 2}$ & 13.2 & 37.3 & 48.1 & 0.34 & 0.78 & 0.16 & 0.13 & 0.06 \\
$\mathbf{1 2 0}$ & 12.9 & 37.4 & 48.3 & 0.32 & 0.83 & 0.15 & 0.10 & 0.06 \\
$\mathbf{1 6 8}$ & 12.9 & 37.9 & 47.8 & 0.39 & 0.77 & 0.16 & 0.10 & 0.06 \\
$\mathbf{2 4 0}$ & 13.1 & 37.2 & 48.1 & 0.34 & 0.78 & 0.17 & 0.28 & 0.05 \\
\hline
\end{tabular}

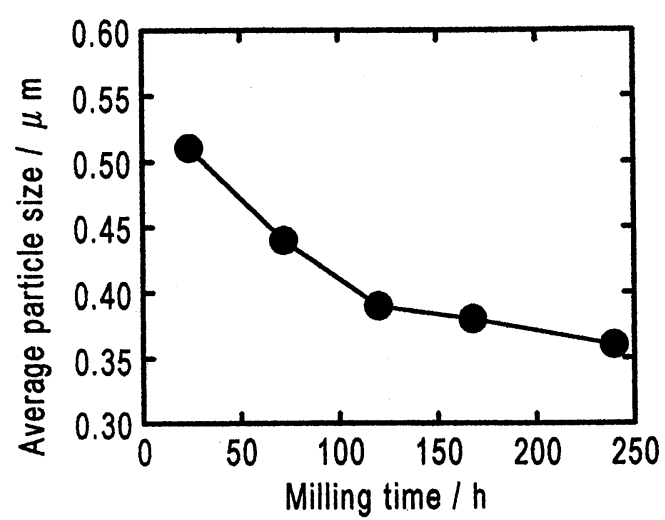

Fig. 2. Relationship between milling time and particle size of ground mixtures.

ding time. Since $\mathrm{Al}_{2} \mathrm{O}_{3}$ content in any of the ground mixtures is predicted to be similar to that of cordierite, the ground mixture seemed not to be contaminated with powder abraded from the grinding media during ball milling.

Figure 2 shows the average particle size of the ground mixtures as a function of milling time. Under the grinding conditions adopted in this experiment, the average particle size of ground mixtures decreased with increasing grinding time. Up to a grinding time of $120 \mathrm{~h}$, the average particle size of the ground mixture shows a marked reduction rate and decreases from 0.51 to $0.39 \mu \mathrm{m}$. However, when grinding time exceeds $120 \mathrm{~h}$, the reduction rate of the average particle size becomes very small and the difference in the average particle size between the ground mixtures at grinding times of 120 and $240 \mathrm{~h}$ is $0.03 \mu \mathrm{m}$. In ball milling of $\mathrm{Al}_{2} \mathrm{O}_{3}$ powder using an alumina pot and alumina balls of 3 $\mathrm{mm}$ in diameter, the reduction rate to an average particle size of $0.5 \mu \mathrm{m}$ was large, but grinding did not progress much under $0.5 \mu \mathrm{m}$. With increasing grinding time, the reduction rate of the average particle size gradually became small because of an increase in the particle number of ground powders. ${ }^{15)}$ Although calcined kaolin and calcined talc seem to be easy-to-grind materials in comparison to alumina, it is thought that the increase in the particle number of the ground mixture results in the small reduction rate of the average particle size with increasing grinding time.

3.2 X-ray diffraction analysis of sintered bodies

Figure 3 shows the X-ray diffraction intensity of each crystalline phase in the bodies sintered at various temperatures from the mixture ground for $24 \mathrm{~h}$ (average particle size of $0.51 \mu \mathrm{m}$ ). The peak intensity of mullite is maximum at $1100^{\circ} \mathrm{C}$ sintering and disappears at $1150^{\circ} \mathrm{C}$. The peak intensities of enstatite and corundum only nominally change from 1050 to $1100^{\circ} \mathrm{C}$, but decrease rapidly at $1150^{\circ} \mathrm{C}$ and disappear at $1200^{\circ} \mathrm{C}$. Spinel and sapphirine are generated in the temperature range from 1100 to $1150^{\circ} \mathrm{C}$, and the amounts generated show maximum values at $1150^{\circ} \mathrm{C}$. Cristobalite, the amount of which is maximum at $1150^{\circ} \mathrm{C}$, is thought to be formed by the crystallization of amorphous silica decomposed from kaolin and talc. At $1200^{\circ} \mathrm{C}, \alpha$-cordierite is formed instead, while the amounts of spinel, sapphirine and cristobalite decrease. Consequently, cristobalite disappears at $1250^{\circ} \mathrm{C}$, the amounts of sapphirine decreases, while the amount of $\alpha$-cordierite increases rapidly. The amount of $\alpha$-cordierite is predicted to reach a maximum at $1300^{\circ} \mathrm{C}$ and then to decrease at $1350^{\circ} \mathrm{C}$ due to particle decomposition. Finally, the body sintered at $1350^{\circ} \mathrm{C}$ consists of $\alpha$-cordierite and a small amount of sapphirine. The 


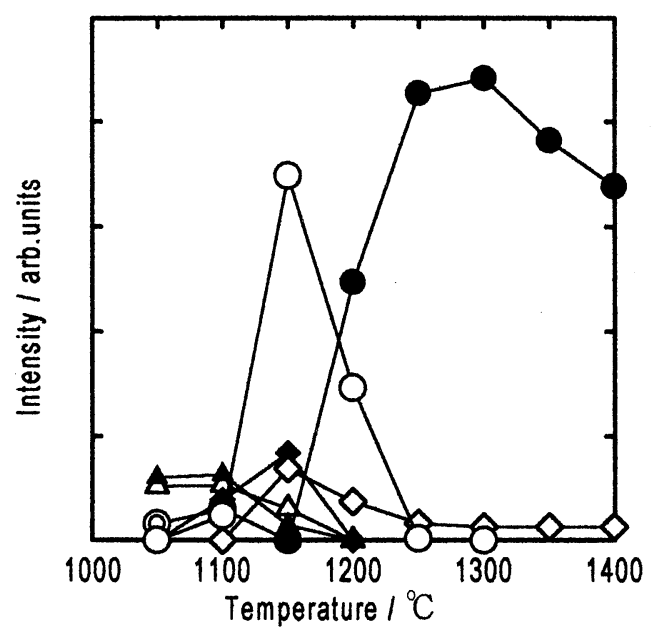

Fig. 3. X-ray diffraction intensity of each crystalline phase in the bodies sintered at various temperatures from the mixture ground for $24 \mathrm{~h}$.

(2) Mullite, $\triangle$ enstatite, $\boldsymbol{\Delta}$ corundum, $\diamond$ spinel, $\diamond$ sapphirine, $\bigcirc$ cristobalite, $\alpha$-cordierite.

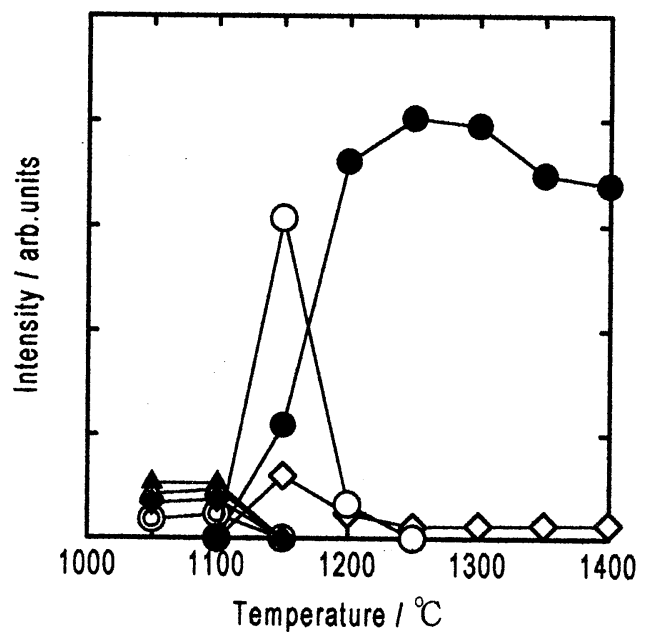

Fig. 4. X-ray diffraction intensity of each crystalline phase in the bodies sintered at various temperatures from the mixture ground for $240 \mathrm{~h}$.

(O) Mullite, $\triangle$ enstatite, $\boldsymbol{\Delta}$ corundum,

$\bigcirc$ cristobalite, $\alpha$-cordierite.

remaining small amount of sapphirine might have resulted from an alumina-rich composition in comparison with the theoretical cordierite composition in this study.

Figure 4 shows the X-ray diffraction intensity of each crystalline phase in the bodies sintered at various temperatures from the mixture ground for $240 \mathrm{~h}$ (average particle size of $0.36 \mu \mathrm{m}$ ). In the case of $0.36 \mu \mathrm{m}$, the spinel phase is detected at $1050^{\circ} \mathrm{C}$, which is $50^{\circ} \mathrm{C}$ lower than that of in the case of $0.51 \mu \mathrm{m}$. The peak intensities of corundum, enstatite, mullite and spinel decrease rapidly from 1100 to $1150^{\circ} \mathrm{C}$, and completely disappear at $1150^{\circ} \mathrm{C}$. The body sintered at $1150^{\circ} \mathrm{C}$ is composed of cristobalite, sapphirine and $\alpha$-cordierite. $\alpha$-cordierite is also crystallized at a temperature $50^{\circ} \mathrm{C}$ lower than that in the case of $0.51 \mu \mathrm{m}$. At sintering temperatures above $1150^{\circ} \mathrm{C}$, the quantitative changes of these three crystalline phases indicate a similar tendency regardless of the particle size of the ground mixtures. The ground mixture with fine powders gives a larger amount of $\alpha$-cordierite at lower temperatures than that with coarse powders.

Sumi et al.9) reported that the mixture of kaolinite and ultrafine particles of magnesium hydroxide gave dense $\alpha$ cordierite ceramics with a relative density of $97.7 \%$ at $1350^{\circ} \mathrm{C}$. In the reaction process of material powders during sintering, $\mu$-cordierite, which was crystallized from the homogeneous amorphous state of what with the $\mathrm{MgO}-$ $\mathrm{Al}_{2} \mathrm{O}_{3}-\mathrm{SiO}_{2}$ composition, was transformed into $\alpha$-cordierite. In this study, $\alpha$-cordierite ceramics were obtained after $1300^{\circ} \mathrm{C}$ sintering without the crystallization of $\mu$-cordierite. It can be concluded that this difference in the crystalline phase during the sintering process depends on the difference in the diffusibility of the $\mathrm{MgO}$ component in magnesium hydroxide and talc.

\subsection{Apparent porosity in sintered bodies}

Figure 5 shows the apparent porosity of the sintered bodies from the mixture with several particle sizes as a function of the sintering temperature. The apparent porosity of the sintered bodies for all ground mixtures decreases rapidly in the temperature range from 1050 to $1150^{\circ} \mathrm{C}$, and then, at a sintering temperature above $1150^{\circ} \mathrm{C}$, the rate of decrease gradually becomes lower. At the same sintering temperature, the apparent porosity decreases with a decrease in the particle size of ground mixtures.

In the sintered bodies obtained from the ground mixture with smaller particle size than $0.39 \mu \mathrm{m}$, the apparent porosity is almost zero at $1200^{\circ} \mathrm{C}$. The apparent porosity for the ground mixture with a particle size of $0.44 \mu \mathrm{m}$ also becomes zero at $1250^{\circ} \mathrm{C}$. Only the apparent porosity of the sintered body of $0.51 \mu \mathrm{m}$ is $14.8 \mathrm{vol} \%$ even after sintering at $1400^{\circ} \mathrm{C}$.

Three kinds of raw materials, ground calcined kaolin with an average particle size of $0.51 \mu \mathrm{m}$, ground calcined talc with $0.50 \mu \mathrm{m}$ and alumina powder with $0.50 \mu \mathrm{m}$, were mixed into the cordierite composition by ball milling for $1 \mathrm{~h}$, and after sintering at $1400^{\circ} \mathrm{C}$, its apparent porosity was about $10 \mathrm{vol} \% .^{13)}$ As mentioned above, in this study the sintered body obtained from the mixture with a particle size of $0.51 \mu \mathrm{m}$ showed a high apparent porosity. According to Sumi et al.,8) bead milling resulted in a finer mixture of kaolinite and basic magnesium carbonate than ball milling, and dense $\alpha$-cordierite ceramics with relative densities $\geqq 95 \%$ were obtained from this fine mixture. If the particle size of the mixture becomes smaller than $0.44 \mu \mathrm{m}$, it would be possible to produce dense, pore-free cordierite ceramics even from natural raw materials.

3.4 Microstructure of cordierite sintered bodies

Figure 6 shows SEM micrographs for the fractured surface of specimens sintered at $1300^{\circ} \mathrm{C}$. In the sintered body

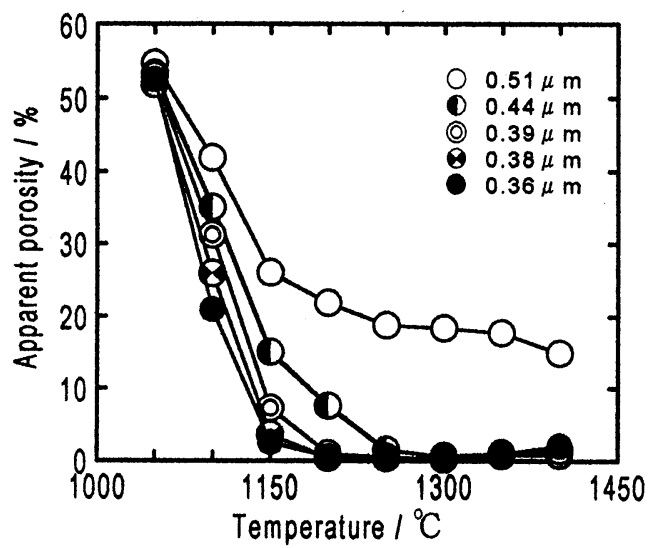

Fig. 5. Effect of particle size of ground mixtures on apparent porosity of sintered bodies. 


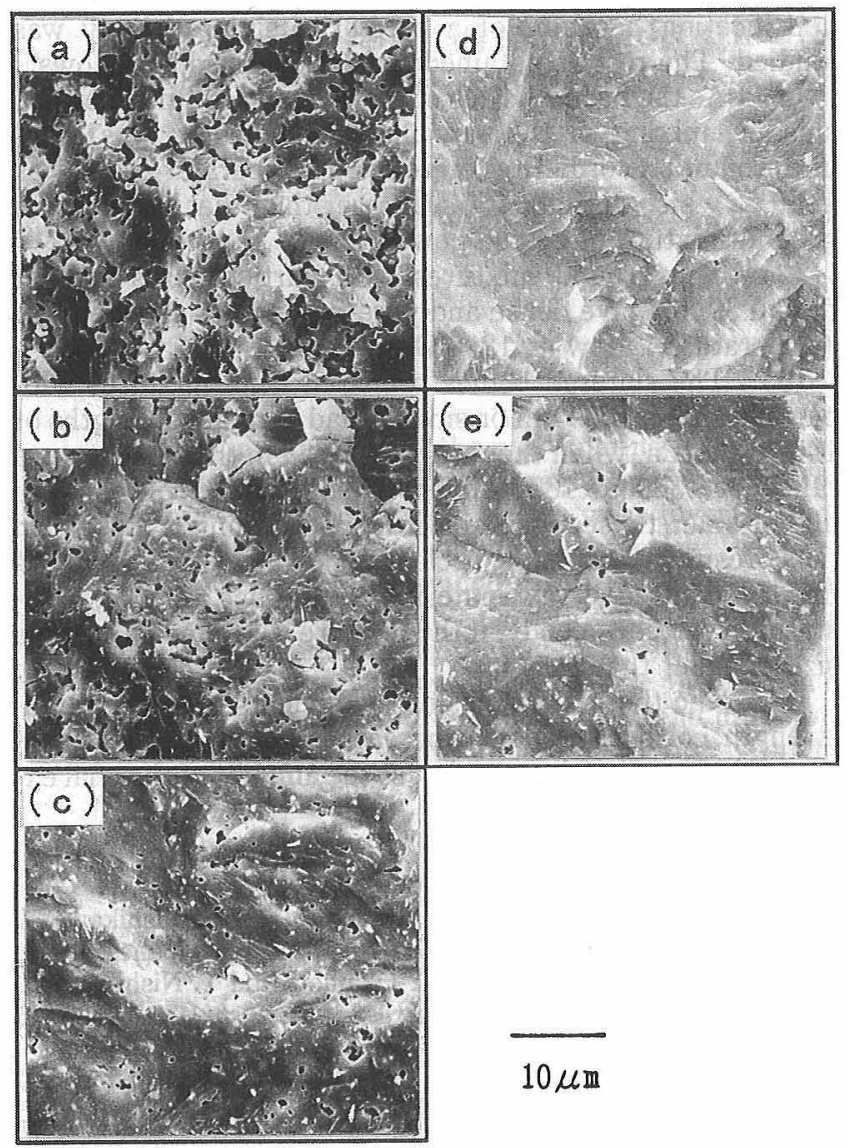

Fig. 6. SEM micrographs for the fractured surface of cordierite bodies sintered at $1300^{\circ} \mathrm{C}$.

(a) $0.51 \mu \mathrm{m}$, (b) $0.44 \mu \mathrm{m}$, (c) $0.39 \mu \mathrm{m}$, (d) $0.38 \mu \mathrm{m}$, (e) $0.36 \mu \mathrm{m}$.

obtained from the ground mixture with an average particle size of $0.51 \mu \mathrm{m}$, many continuous pores are observed. As the particle size of ground mixtures decreases from 0.44 to $0.39 \mu \mathrm{m}$, the number of pores decreases considerably, and closed pores become smaller and spherical in shape. In particular, in the sintered body obtained from mixtures with average particle size of $0.38 \mu \mathrm{m}$, the number of pore is the least. Inversely, in the case of $0.36 \mu \mathrm{m}$, both the number and the size of pores increase slightly. These SEM micrographs indicate that dense $\alpha$-cordierite ceramics are produced from ground mixtures with an average particle size below $0.44 \mu \mathrm{m}$, in the same manner in the experimental result for apparent porosity shown in Fig. 5.

Figure 7 shows SEM micrographs for the microstructures of two sintered bodies at $1300^{\circ} \mathrm{C}$. In micrograph (a) for the sintered body obtained from a mixture with average particle size of $0.51 \mu \mathrm{m}$, the grain size of cordierite is not uniform and is in the range from 0.5 to $3 \mu \mathrm{m}$. This seems to be a result of the insufficient mixing and grinding of raw materials due to short grinding time. In particular, the grain size of cordierite close to pores is very large. As most pores are formed by the melting of talc particles, ${ }^{11)}$ it is considered that the large cordierite grain grew in the liquid phase formed by melting of the talc particles. In micrograph (b) of the sintered body obtained from a mixture with average particle size of $0.36 \mu \mathrm{m}$, the grain size of cordierite is 0.5 to $1 \mu \mathrm{m}$ and uniform compared with the body from $0.51 \mu \mathrm{m}$. A cordierite body with small uniform grains was obtained using a finer-powder ground mixture.

Although microcracks in cordierite ceramics are sometimes caused by the thermal expansion anisotropy of
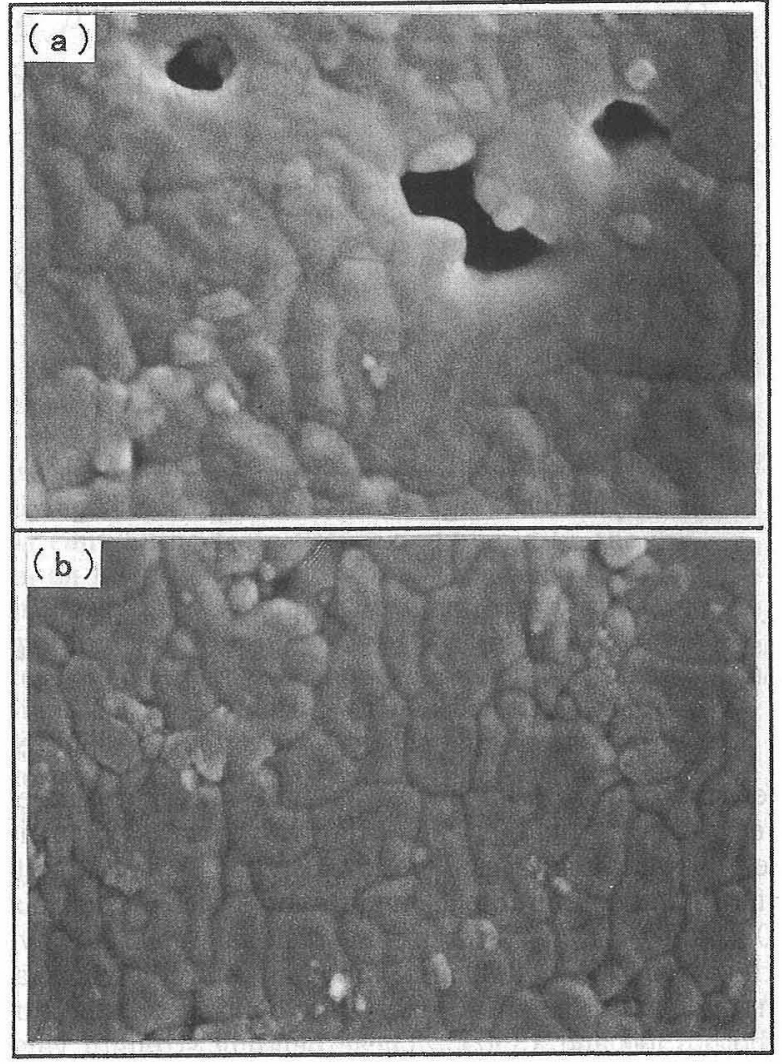

$1 \mu \mathrm{m}$

Fig. 7. Cordierite grains of bodies sintered at $1300^{\circ} \mathrm{C}$. (a) $0.51 \mu \mathrm{m}$, (b) $0.36 \mu \mathrm{m}$.

cordierite crystals, ${ }^{16)}$ there are no microcracks in the sintered bodies, with particle sizes of 0.51 and $0.36 \mu \mathrm{m}$, as shown in Fig. 7. This is considered to result in the small grain size of cordierite in the sintered body compared with the critical size which generates microcracks due to the thermal expansion anisotropy of the crystal.

3.5 Bending strength and thermal expansion coefficient of cordierite bodies

Figure 8 shows the bending strengths of cordierite bodies sintered at $1300^{\circ} \mathrm{C}$ and $1350^{\circ} \mathrm{C}$. The bending

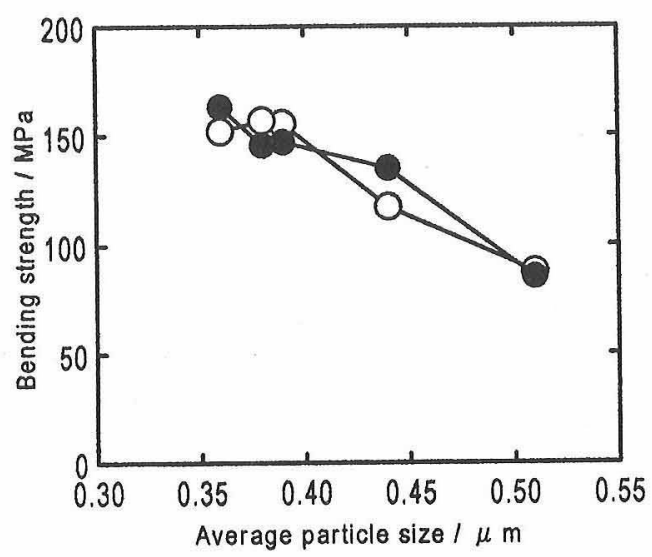

Fig. 8. Effect of particles size of ground mixtures on bending strength of cordierite bodies sintered at $1300^{\circ} \mathrm{C}(\mathrm{O})$ and $1350^{\circ} \mathrm{C}$ (O). 


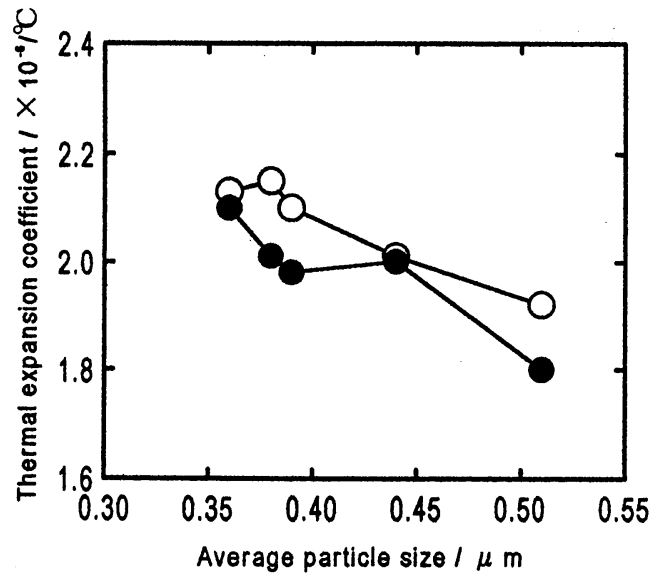

Fig. 9. Effect of particle size of ground mixtures on thermal expansion coeffecient of cordierite bodies sintered at $1300^{\circ} \mathrm{C}(\mathrm{O})$ and $1350^{\circ} \mathrm{C}(\mathrm{O})$

strengths of cordierite bodies at both sintering temperatures increase from 80 to $160 \mathrm{MPa}$ with decreasing particle size of ground mixtures. The low bending strengths in the sintered bodies from the ground mixture with particle sizes of 0.51 and $0.44 \mu \mathrm{m}$ result in some residual pores. However, in the cases of $0.39,0.38$ and $0.36 \mu \mathrm{m}$, the fired bodies have bending strengths of $140-160 \mathrm{MPa}$ at firing temperatures of both 1300 and $1350^{\circ} \mathrm{C}$. These bending strength values are larger than that of cordierite glass-ceramic.1)

Figure 9 shows the thermal expansion coefficients of cordierite bodies sintered at 1300 and $1350^{\circ} \mathrm{C}$. The thermal expansion coefficients increase from 1.92 to $2.13 \times 10^{-6} /{ }^{\circ} \mathrm{C}$ for bodies sintered at $1300^{\circ} \mathrm{C}$, and from 1.80 to $2.10 \times 10^{-6} /{ }^{\circ} \mathrm{C}$ for that sintered at $1350^{\circ} \mathrm{C}$, with decreasing particle size of the ground mixtures. The thermal expansion coefficient of the sintered body is a larger value in denser cordierite bodies.

The thermal expansion coefficient, $2.1 \times 10^{-6} /{ }^{\circ} \mathrm{C}$, of densest cordierite body obtained in this experiment is somewhat larger than that of a dense cordierite body with a theoretical cordierite composition, $1.7-1.8 \times 10^{-6} /{ }^{\circ} \mathrm{C}(25-$ $\left.900^{\circ} \mathrm{C}\right){ }^{17), 18)}$ It is thought that the cordierite body in this study contains a small amount of sapphirine with a thermal expansion coefficient as high as $5.4 \times 10^{-6} /{ }^{\circ} \mathrm{C} .{ }^{19}$ )

The thermal expansion coefficients show a tendency to increase in dense and pore-free bodies obtained from ground mixtures with fine particles. The small amount of thermal expansion of the cordierite body is caused partly by its thermal expansion anisotropy. On heating, cordierite shows a small amount of thermal expansion in the direction of the $a$ axis but slight contraction in the direction of the $c$-axis. ${ }^{20), 21)}$ It is considered that such expansion and contraction of the cordierite crystal easily occur in the sintered bodies with high porosity, and consequently, the thermal expansion coefficient of the body may decrease with increasing particle size of the ground mixture. On the other hand, the thermal expansion coefficient of a dense cordierite body obtained from a ground mixture with fine particles is a large value, because expansion and contraction of the crystal are difficult to occur.

\section{Conclusions}

Mixtures of calcined kaolin, calcined talc and alumina were ground into a submicron powder by ball milling, and the effect of the particle size of the ground mixture on the densification behavior of a cordierite sintered body was studied. The results obtained are summarized as follows.

(1) As the particle sizes of the ground mixtures became smaller, mixing of the raw material powders was more uniform and $\alpha$-cordierite formed at a temperature as low as $1150^{\circ} \mathrm{C}$, which was about $50^{\circ} \mathrm{C}$ lower than that of the usual ground mixture of coarse powders.

(2) The ground mixtures with particle sizes smaller than $0.39 \mu \mathrm{m}$ gave dense and pore-free bodies sintered at a temperature as low as $1200^{\circ} \mathrm{C}$.

(3) The sintered bodies prepared from mixtures with particle size of $0.39 \mu \mathrm{m}$ or smaller had bending strengths of 140-160 MPa, when they were sintered in the temperature range of 1300 to $1350^{\circ} \mathrm{C}$. Those bending strengths were higher than those of cordierite glass-ceramics. Based on these results obtained, it is clear concluded that kaolin and talc can be used as raw materials to produce a dense, highstrength cordierite body, if the mixture is ground to particle sizes smaller than $0.39 \mu \mathrm{m}$.

(4) The thermal expansion coefficients of dense, highstrength cordierite bodies increased, because anisotropic thermal expansion does not lower the amount of thermal expansion in pore-free bodies.

\section{References}

1) K. Hayashi, T. Yamada, Y. Okamoto and T. Nishikawa, J. Ceram. Soc. Japan, 101, 1264-67 (1993) [in Japanese].

2) K. Hayashi, T. Nishiyama, Y.Okamoto and T. Nishikawa, $J$. Ceram. Soc. Japan (Seramikkusu Ronbunshi), 97, 328-33 (1989) [in Japanese].

3) K. Hayashi, M. Okuno, Y. Okamoto and T. Nishikawa, $J$. Ceram. Soc. Japan (Seramikkusu Ronbunshi), 98, 1070-75 (1990).

4) H. Suzuki, K. Ota and H. Saito, J. Ceram. Soc. Japan (YogyoKyokai-Shi), 95, 163-69 (1987).

5) H. Suzuki, K. Ota and H. Saito, J. Ceram. Soc. Japan (YogyoKyokai-Shi), 95, 170-75 (1987).

6) H. Suzuki, H. Saito, J. Ceram. Soc. Japan (Seramikkusu Ronbunshi), 96, 659-65 (1988) [in Japanese].

7) M. Awano, H. Takagi and Y. Kuwahara, J. Am. Ceram. Soc., 75, 2535-40 (1992).

8) K. Sumi, Y. Kobayashi and E. Kato, J. Ceram. Soc. Japan, 106, 89-93 (1998) [in Japanese].

9) K. Sumi, Y. Kobayashi and E. Kato, J. Am. Ceram. Soc., 81, 1029-32 (1998).

10) K. Sumi, Y. Kobayashi and E. Kato, J. Ceram. Soc. Japan, 106, 693-97 (1998) [in Japanese].

11) M. Nakahara, Y. Hashizuka, Y. Kondo and K. Hamano, $J$. Ceram. Soc. Japan, 102, 18-22 (1994) [in Japanese].

12) M. Nakahara, Y. Kondo and K. Hamano, J. Ceram. Soc. Japan, 103, 1051-56 (1995) [in Japanese].

13) M. Nakahara, Y. Kondo and K. Hamano, J. Ceram. Soc. Japan, 106, 787-91 (1998) [in Japanese].

14) I. M. Lachman, R. D. Bagley and M. Lewis, Am. Ceram. Soc. Bull., 60, 202-05 (1981).

15) K. Yokota and Y. Kondo, Powder Powder Metall., 45, 680-84 (1998).

16) S. Udagawa and H. Ikawa, Ceramics Japan, 14, 967-76 (1979) [in Japanese].

17) S. Udagawa, H. Ikawa and H. Miyagawa, J. Mater. Sci., 10, 214-20 (1973).

18) D. L. Evans, G. R. Fisher, J. E. Geiger and F. W. Martin, J. Am. Ceram. Soc., 63, 629-34 (1980).

19) K. Hayashi, T. Tanaka and Y. Okamoto, Proceedings of the 8th Fall Meeting of the Ceramic Society of Japan (1995) p. 136.

20) M. F. Hochella, Jr., G. E. Brown, Jr., F. K. Ross and G. V. Gibbs, Am. Mineral., 64, 337-51 (1979).

21) S. Udagawa and H. Ikawa, Proceedings of the 18th Symposium on the Basis of Ceramics, Ceramic Society of Japan (1980) p. 8. 